Article

\title{
Consumers' Perspective on Full-Scale Adoption of Smart Meters: A Case Study in Västerås, Sweden
}

\author{
Iana Vassileva * and Javier Campillo \\ Received: 16 October 2015; Accepted: 30 December 2015; Published: 6 January 2016 \\ Academic Editor: Damien Giurco \\ School of Sustainable Development of Society and Technology, Mälardalen University, P.O. Box 883, \\ Västerås SE-721 23, Sweden; javiercjz@gmail.com \\ * Correspondence: iana.vassileva@gmail.com; Tel.: +46-736-469-241
}

\begin{abstract}
Large-scale deployment of reliable smart electricity metering networks has been considered as the first step towards a smart, integrated and efficient grid. On the consumer's side, however, the real impact is still uncertain and limited. This paper evaluates the consumer's perspective in the city of Västerås, Sweden, where full implementation of smart meters has been reached. New services, such as consumption feedback and the possibility to choose dynamic electricity pricing contracts, have been available from the adoption of this infrastructure. A web-based survey evaluating customers' perception of these new services was carried out. The survey included consumers' personal information, preferences about the type of information and the frequency of delivery and the preference for electricity pricing contracts. The results showed that the electricity consumption information offered by distribution system operators (DSOs) today is not detailed enough for customers to react accordingly. Additionally, while variable pricing contracts are becoming more popular, the available pricing schemes do not encourage customers to increase their consumption flexibility. Therefore, more detailed information from the smart meters should be made available, including disaggregated electricity consumption per appliance that would allow consumers to have more control over their energy consumption activities.
\end{abstract}

Keywords: electricity users; energy efficiency; smart meter benefits; energy consumption feedback; variable price; demand response

\section{Introduction}

The total energy consumption during 2011 in the residential and services sector (residential and commercial premises, holiday homes and land use) reached 144 TWh or 38\% of Sweden's total final energy usage [1]. Moreover, household electricity has increased from 9 to 21 TWh between 1970 and 2011. Although there has been an increase in the efficiency of household appliances, the increasing population and amount of appliances per household have resulted in a negative impact on energy efficiency trends [2]. These among other trends are considered as the reasons why the "20-20-20" goals set by the European Union all have been reached, but for the goal regarding a " $20 \%$ increase in energy efficiency by 2020" [3]. As part of the strategies used to reach the $20 \%$ reduction in consumption, the European Energy Efficiency Directive states that "easy and free-of-charge access to data on real-time and historical energy consumption" should be available from a smart metering infrastructure; provision implemented by the Member States in June 2014 [4].

It is estimated that between 90 and 130 million smart meters will be installed worldwide annually until 2022 [5]. Furthermore, $80 \%$ of the households in Europe will use a smart meter by the same year [6].

One of the greatest advantages of smart meters, when compared to traditional electricity meters, is their capability to collect and store detailed electricity consumption data that can be frequently 
accessed by the consumers provided by the distribution system operators (DSOs) through web-sites, bills, mobile applications, etc. [7,8]. The rollout of smart meters has had varying purposes in different countries. In California, USA, the main purpose with the introduction of smart meters was demand management; in Italy, reduction of energy theft; in Ireland, a combination of accurate billing and demand management [9]. In Sweden, through legislation introduced in June 2009, it was required that households should receive accurate monthly electricity bills based on monthly readings and not yearly estimations, by means decided by the energy market [10]. The legal resolution to make monthly electricity meter readings available to customers led to the decision by distribution companies to introduce smart meters to all Swedish customers [11]. The main driver behind the decision was based on the customers' dissatisfaction and complaints regarding the billing process and for helping them increase their awareness of energy consumption [12]. Other objectives of the regulation regarding monthly meter readings for household consumers included: estimated savings of $2 \%-3 \%$ (if bills included statistics about the consumption); new development of electricity and network tariffs; and an improved electricity market [13].

When it comes to the energy market in Sweden, it was deregulated in 1996, meaning that both electricity production and retail have been subject to competition after the reform. The electricity price is mainly determined by supply and demand on an hourly basis on the NordPool spot market for the next 24-h period and also by the suppliers' bilateral agreements with producers, the supplier's own production and on the current taxes and fees.

In any case, one of the main limitations when analyzing the overall impacts of smart meters is the lack of careful consideration of human impact and behavioral barriers [14]. Additionally, the European Commission has suggested that some of the current methods of individual metering and billing do not help consumers save energy and are, in some countries, one of the main obstacles to mass-market diffusion of smart meters [15]. An important concern among users regarding smart meter adoption is related to privacy issues around the data obtained from the hourly energy consumption readings. Several studies [14,16-18] have demonstrated the potential of identifying patterns associated with users' behavior at home from smart meter readings (at what time the family cooks dinner, at what time they wake up on weekends, etc.) that could result in increased privacy concerns among the users. The privacy concerns about this information stretch from security issues about burglars finding out when homes are not occupied, to family matters where one partner might investigate the other's behavior [19]. These and other limitations have encouraged consumers to consider in many cases not to make use of all the possible advantages of the smart meters. Despite electricity bills becoming more accurate and not based on estimated values and some consumers having access to statistics about their own consumption, there is still potential for achieving larger savings, increased energy efficiency and greater consumer flexibility.

There are two main gaps found in the research that still remain. First is the evaluation of consumer interaction with smart meters and the service obtained from the meters, in countries where this type of metering infrastructure has been used for a long period of time. The second is based on the consumers' preferences and feedback, how to improve future smart meters deployment and their use, in order to reach better results regarding energy efficiency through increased consumers' knowledge regarding appliance consumption and connection to their everyday activities.

This paper aims to bridge these gaps by analyzing the impact that smart meters have on consumers by evaluating users' perspective collected through a survey carried out among residential consumers in Västerås, Sweden. The results presented in this work could help future policy development, energy efficiency campaigns and countries with plans for or in their initial stages of smart meters' rollout and in their efforts towards enhancing consumer empowerment through better targeted awareness campaigns, demand response programs, etc. The paper is organized as follows: Sections 1.1 and 1.2 include background information regarding pricing schemes and feedback, respectively. Section 2 includes information regarding the survey formulation, followed by Section 3, where the main outcomes have been discussed, divided into general household information, responses related to electricity price 
contracts and feedback preferences. The last section includes the conclusions and recommendations for adoption strategies in other countries.

\subsection{Variable Electricity Tariffs}

Large-scale adoption of smart meters has provided DSOs with the opportunity to offer different types of electricity pricing contracts, in addition to traditional fixed-price contracts. This allows customers to have access to electricity prices that are closer to the production costs. Furthermore, retailers can introduce different strategies that encourage their customers to reduce electricity consumption during critical peak times, thus providing additional demand flexibility that helps balancing load and supply [20].

Different levels of consumer flexibility have become one of the more relevant challenges of current electrical systems due to the increased use of centralized and decentralized renewable energy resources, mainly wind farms and solar plants, and causing unprecedented fluctuations in electricity supply. Fixed electricity tariffs, as well as low-carbon electricity mix, low electricity prices and lack of information, do not help consumers perceive the importance of adapting their activities and behaviors in order to match generation levels, translating into negative impacts on the power systems, as for instance, quality issues, lost load or lost production [21,22].

One of the most frequently-utilized methods for increasing consumer flexibility and for encouraging consumers to become an active part of the electricity systems is through "demand side management" programs. Demand response is considered one of the demand side resources or mechanisms that are made possible through the use of smart grid-related technology and activities. A more specific definition has been provided by the Federal Energy Regulatory Commission (FERC), where demand response is defined as the changes in electricity consumption by the end-use consumers from their normal consumption patterns in response to changes in the price of electricity over time or to incentive payments designed to introduce lower electricity use at times of high wholesale market prices or with system reliability issues [23].

Some of the most common tariffs currently used to promote increased demand response are time-of-use (TOU), where two or more tariffs are used for high-peak and low-peak times; critical peak pricing (CPP), where higher prices might be imposed during periods with low or high temperatures; and real-time pricing (RTP), where the spot market price is applied. Consumers then have the incentive to respond to short-term price variations by decreasing their consumption during peak periods or by shifting it to off-peak periods. In order to increase users' flexibility and select the best pricing scheme while maintaining a stable electricity demand, energy usage patterns and available tariffs have to be studied together in order to allow the consumers to get important economic benefits (especially in cases where households rely on electricity for heating) [24]. Consumer electricity price-responsiveness has been extensively researched and summarized in Hu et al. [25]; where the lack of customer support in demand response programs has been identified as a major barrier and explained by price disconnection and electricity provider disincentive. In fact, most electricity consumers are still unfamiliar with the concept of smart grids and smart meters, as well as the reasons for and potential benefits from demand response and demand flexibility. Additionally, the level of flexibility and consumption pattern shift will mainly depend on the consumers' needs, their trust in the electricity provider and different incentives: economic, environmental and societal, among others [26]. Based on the previously-mentioned factors, the investments needed in some cases (e.g., in different automation solutions or the change of appliances) were perceived to be too high by consumers or even to reduce the consumers' comfort, as described by Peters et al. [27].

Despite the possibility of changing the electricity suppliers, the increase in the number of customers that changed their supplier has been rather slow: for the period March 2013 to February 2014 , a total of 499,984 households had changed their electricity supplier ( $9 \%$ more than the same period, a year before) [28]. When it comes to changes in the type of contract, since the electricity market deregulation and the full smart meter rollout in Sweden, there has been a significant transition in the 
amount of customers shifting from default (fixed-price) contracts to other types, mainly variable-price contracts. This is due to the rather low average prices of the last few years. Other types of fixed-period fixed-price contracts (one, two and three years) remained stable between the years 2008 and 2011, with a slight shift towards variable pricing contracts in the years 2012-2014 (see Figure 1) [28].

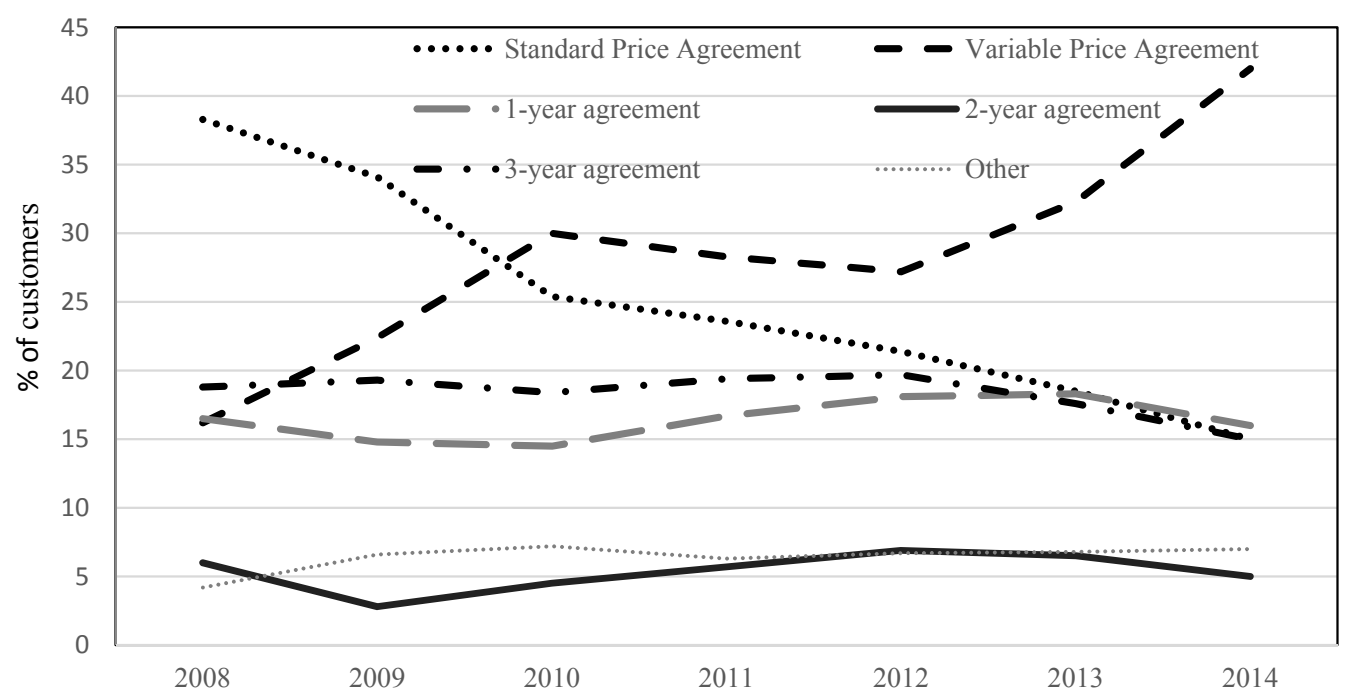

Figure 1. Distribution of domestic customers by type of contract in December 2014.

However, even though variable pricing contracts are the most preferred, this type of contract is based on the monthly average price of the electricity market, plus a retailer fee. Therefore, although it is referred to as "variable", since it is not based on the TOU of electricity, it does not encourage customers to change their electricity consumption behavior. Additional factors, such as the relatively low electricity prices compared to other countries in Europe and the lack of specific information regarding savings, benefits, targeted actions, etc., hinder consumers' demand flexibility based on electricity prices. The lack of involvement of the consumers in the development process or the combination with other services based on the consumers' characteristics and interests (options for energy storage; appliances control; security and remote monitoring) are also contributing to customers' lack of flexibility, as mentioned by Heiskanen and Matschoss [29]. Additionally, in a study carried out by Broman Toft et al. [30], where people's smart grid technology acceptance was investigated, there was a lower moral obligation to install such technologies in Norwegian participants than in citizens in Denmark and Switzerland. The overall little focus on the environmental impact of electricity consumption among Norwegian citizens has been explained by abundant and inexpensive electricity from renewable sources, making it sustainable and, thus, suppressing the consumers' "guilt" for having high consumption [31]. These findings could be applicable to their Swedish neighbors, where in 2013 , the electricity mix consisted of $41 \%$ hydropower, $43 \%$ nuclear and $7 \%$ wind [32].

\subsection{Information and Feedback}

For most customers, electricity is "invisible" and a "product" not actively consumed, and it is therefore difficult for people to connect their specific activities to electricity consumption, as discussed by Hargreaves et al. [33]. A way to increase the "visibility" of electricity consumption is through feedback, which can be facilitated by (although not limited to) the use of smart electricity meters.

Feedback is considered as the method of providing information, knowledge or contributing in any other way to changing consumers' behavior and energy consumption habits. The main objectives when providing electricity consumption feedback are to enable and motivate households to save energy, shift their electricity loads, increase their awareness and help them make use of the benefits associated with smart meters [34]. The savings in electricity consumption reached from providing consumers 
with feedback differ between different studies depending on factors, such as type of feedback and the way the feedback was delivered, among others. Some results have shown savings between $10 \%$ and $20 \%$ [35-37]; on the other hand, providing indirect feedback, as with the electricity bills, for example, has reached savings of $0 \%-10 \%$ [35]. In some cases, the use of real-time consumption information using in-home displays (IHD) has only succeeded in reducing consumption by an average of $8 \%$ [38]. In Sweden, however, the average end-user does not have access to the household's consumption disaggregated by appliance. In Swedish households connected to the district heating network, it was estimated that in the year 2006, detached houses typically used approximately $1000 \mathrm{kWh}$ /year for lighting ( $23 \%$ of the total electricity used); $860 \mathrm{kWh} /$ year for cold appliances; followed by $300 \mathrm{kWh} /$ year used for cooking and washing each. In apartments, the cold appliances were responsible for approximately $710 \mathrm{kWh}$ /year (24\% of the total electricity); $680 \mathrm{kWh}$ /year were used for lighting; $270 \mathrm{kWh} /$ year are used for cooking and $210 \mathrm{kWh}$ /year for washing [39]. It is important to mention that $22 \%$ of the electricity used in detached houses and $10 \%$ in the case of apartments were not disaggregated [39]. In Sweden, consumption data, collected from the smart meters, are commonly transformed into different graphs, mainly as monthly comparisons, and presented to the consumers in different formats and channels: dedicated web-sites (usually connected to the DSO's homepage) and mobile phone applications, electricity bills or, in some cases, in-home displays showing real-time consumption. However, the usual procedure with the offered IHD and real-time consumption is that they have to be purchased by the consumers themselves. The prices for purchasing the IHD are often regarded as too high by consumers, especially considering that electricity end-users typically do not find the costs profitable enough if compared to the potential savings associated with their energy reductions [40]. In cases where web-based feedback was provided (which is currently the most common method used by Swedish electricity providers), the interest shown by the consumers is, in general, rather low. In a study carried out in Sweden, where consumers had access to web-based feedback, of the apartment owners (60 in total), only $16.7 \%$ accessed their consumption feedback [36]. The situation is relatively better among house owners: $36 \%$ visited the web-based information at least once; this difference is probably due to energy consumption in houses being higher than in apartments, making consumers in general more concerned about their expenses associated with electricity [36].

Several studies have analyzed how consumption information and feedback affect consumers' attitudes towards reducing energy usage. These studies conclude that the results are highly dependent on the user preferences regarding the type of graphic design and colors [41]; the frequency at which the information is provided [42]; and the type of device used to provide the information [43].

Some of the main challenges that still remain include finding a way to reach larger groups of end-users when providing feedback and increasing their awareness regarding higher energy efficiency and economic savings.

DSOs in Sweden, when offering "variable-price" contracts based on hourly market variations, usually do not supply additional information, as, for instance, how the different prices will be made available to the users, what activities can be shifted when electricity prices are too high, etc. This lack of information regarding electricity prices and measures to save energy prevent from increasing consumers' engagement and sustain the anxiety associated with not knowing the electricity prices and how to react accordingly.

\section{Survey Description}

The objective of the survey used in this study was to understand the current perceptions and preferences of smart meter users. Therefore, the survey approach used was targeted to provide an overview of how (e.g., how current consumers would like to receive information on their consumption) and what (e.g., the type of information the consumers would like to have access to) is happening in relation to the full-scale rollout of smart meters in Sweden [44,45]. The online survey, carried out between April and May 2014, was developed in collaboration with the local city-owned electric power and district heating provider (located in the city of Västerås). The main channel of the survey 
distribution was through the magazine issued by the electricity provider quarterly and also on the provider's homepage. The online survey platform used for creating the survey, Netigate, applies two methods for the diffusion of online surveys. The first method, via email, only registers one response, regardless of the amount of times the survey link is clicked. The second method is via direct link, in which case, the IP address and cookies are used as a duplicating-prevention mechanism. In this case, multiple submissions were prevented in order to avoid the same person replying several times. In general, web-based surveys have been considered to display higher levels of data reliability than, for instance, phone surveys; some of the reasons for that are that the respondents feel greater privacy protection when using web-based surveys [46]. Of the main drawbacks with the online survey used is the difficulty to establish the exact response rate due to the challenge of knowing exactly how many individuals might have seen the survey, or the link to the survey, but decided not to participate. However, some studies estimate a response rate through considering the number of times the link was accessed; the response rate is then estimated by dividing the number of returned surveys by the visitation count [47]. Applying this method, after a period of one month, 293 "hits" were registered, and 164 questionnaires were submitted (56.3\% response rate) with complete answers. Only one of the total submitted questionnaires (165) was eliminated due to incomplete answers. Only consumers paying for the electricity consumption themselves (not included in their monthly rent) were included in the study.

Considering that the population of the city of Västerås is about 142,131 people [48], the obtained answers are considered representative of the city's population with a confidence interval of 7.8 and a confidence level of $95 \%$ [49]. The questions included in the survey were based on surveys carried out in Sweden in previous years $[36,43]$ and updated based on the topic analyzed in this study, with the help of the marketing department of the electricity provider. The survey contained questions that included open-ended answers (e.g., size of the household), but most of the questions contained multiple-choice answers. The respondents were also given the option to write additional information and answers to most of the questions.

Bearing in mind the main advantages provided with the smart meters' rollout for electricity end-users (feedback and access to variable prices) and in order to understand their current status and future intentions, the questions included in the survey targeted firstly basic personal and household information (age, gender, number of children, type of household and type of heating, among others). The customers were also asked to answer if they consider that saving energy is an important issue; if they were receiving their electricity bills in a paper format or electronically; if their electricity contract was based on fixed or variable price and if, in case they had fixed price contracts, they had the intention to switch to variable price within the next year. The rest of the questions focused on the frequency that the respondents preferred for receiving information about their consumption (daily, weekly, monthly, etc.), the way they wanted to receive it (in-home displays, "apps", etc.) and also the type of information they think would help them reduce their electricity usage: comparison to their neighbors' electricity consumption, electricity saving tips based on their own consumption, detailed information about the consumption of their electrical appliances or comparisons with their own electricity consumption from previous periods. Finally, the consumers were asked if they were currently using any device to follow up on their own electricity consumption. The number of questions was kept low in order to avoid a loss of interest by the respondents, which may lead to them skipping questions or not completing the survey. The survey was available for answering for a period of one month, and a limited number of free movie tickets were used as an incentive.

One limitation with the sample is that it includes only customers of a specific electricity provider. However, given the fact that most electricity providers in Sweden offer a very similar service and the same access to information to the consumers, it is expected that the opinions and preferences collected in this study are shared by other end-users in Sweden. 


\section{Results and Discussion}

In order to obtain a better view of how to make better use of the data collected by the smart electricity meters, the results from the survey carried out in this work were analyzed focusing on the previously-described benefits for the consumers: opportunity to choose variable electricity prices and electricity consumption feedback.

\subsection{Respondents and Dwelling Characteristics}

The demographic information extracted from the responses showed that the age of the majority of the respondents is between $36-45$ and $46-55$ years: with $28 \%$ and $27 \%$ of respondents respectively; $24 \%$ of the respondents were in the age group of 26-35 years (see Figure 2 ). The mean age of the respondents is 44 years old; the age distribution of the sample following a normal distribution.

The low response rate within the group $66+$ might be an indicator of a low interest in the topic at hand or difficulties completing the survey, as it was online. Regarding the respondents in the age group -25 , the low response rate could be explained by the fact that the survey targeted customers of the local electricity provider, while consumers within this group are expected to live with their parents or in student accommodations, where electricity is typically included in the monthly rent.

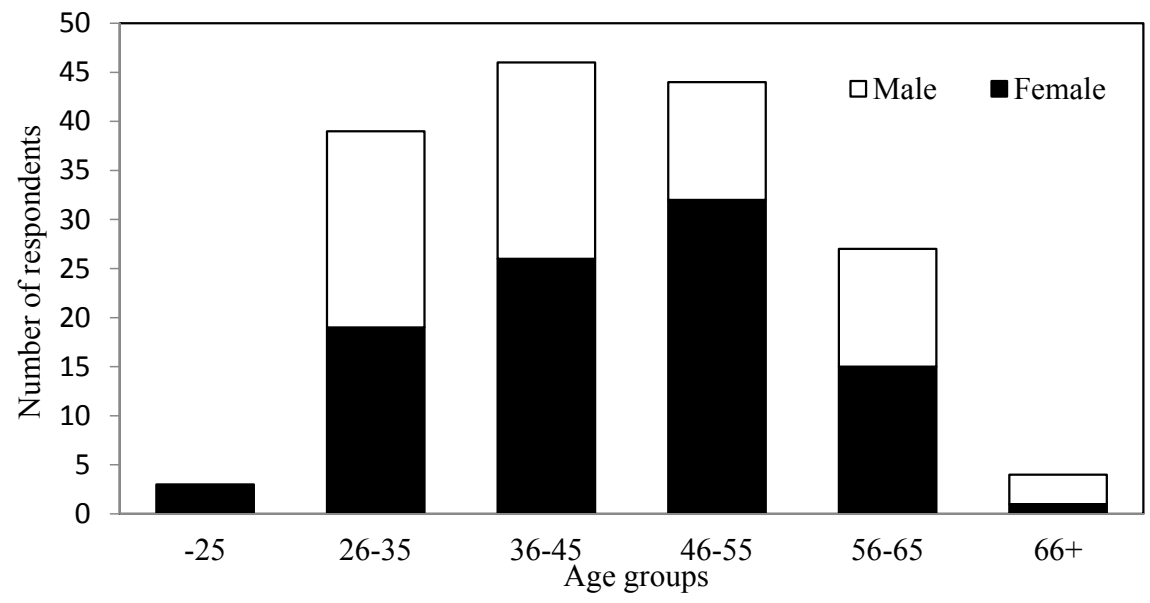

Figure 2. Age and gender distribution of the survey respondents $(N=164)$.

A difference of $20 \%$ was found between the number of female and male respondents (59\% female and $41 \%$ male), making the sample relatively balanced in terms of gender.

The number of people living in a household has been estimated to have a large impact on the overall electricity consumption and, therefore, on the economic value of saving energy [50]; for this reason, the survey included questions targeting the households' composition. Of the total respondents $(N=164)$, a large percentage lived in two-member families $(41 \%)$, followed by families with four and three members, $20 \%$ and $18.3 \%$, respectively. These results are in line with the average Swedish household composition of two members per household, one of the smallest when compared to other European countries [51].

The average dwelling size was $180 \mathrm{~m}^{2}$, which is above the average of $68 \mathrm{~m}^{2}$ for multi-dwelling buildings and $122 \mathrm{~m}^{2}$ for one- or two-dwelling buildings in Sweden [52]. Results presented in previous studies have indicated that consumers living in houses typically have a greater interest in energy-saving topics, mainly due to high electricity consumption levels, as well as larger saving potentials [36]. Therefore, the participants in the survey were asked about their home type, the results showing that $63.4 \%$ of the total lived in detached houses, while $20.1 \%$ lived in apartments, confirming this higher rate of interest of consumers living in houses, for participating in energy-related topics. In order to find out more about the respondents' interest in energy-related topics, consumers were additionally asked how important reducing their electricity consumption is to them. Eighty-nine 
percent of the consumers living in houses considered saving electricity as a "very important" or "important" topic; $10 \%$ found it "less important". A similar percentage, $80 \%$ of the respondents living in apartments, answered that saving electricity is "very important" or "important". Seven percent of apartment residents answered that saving electricity was "not important at all".

Since, for countries like Sweden, significant electricity reductions and saving potential are dependent on the household's main source of heating, the respondents were asked whether they use district heating or electric heating, the results showing that $71 \%$ of the people used district heating as a main source of heating, while 31\% relied on electricity for heating. Moreover, all respondents using any form of electrical heating system considered reducing their electricity consumption "very important" or "important". These findings are interesting for future policy and energy-saving campaigns: target groups living in houses and those using electric heating, as they should be easier to engage.

\subsection{Variable Price}

While the participation of customers on variable-price contracts accounts for more than $30 \%$ of the respondents in this study, out of the $61 \%$ that still preferred fixed-price contracts, only $13 \%$ were willing to switch to variable pricing. One of the factors explaining this is that the DSO has not included any additional incentives, tools or information to help their customers follow the hourly development of electricity prices, thus failing to properly engage consumers with variable-price contracts.

In order to find any possible gender- and/or age-related differences influencing the decision for choosing fixed- or variable-price contracts, the responses were further analyzed based on these consumer characteristics (see Figures 3 and 4). Responses from participants in the -25 and $66+$ age groups were eliminated due to their low representativeness.

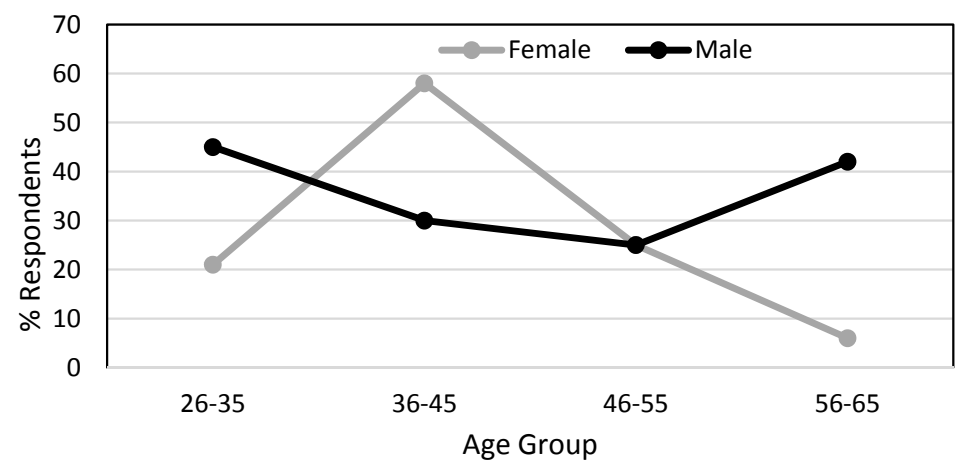

Figure 3. Variable electricity price contracts chosen by the respondents grouped by age and gender.

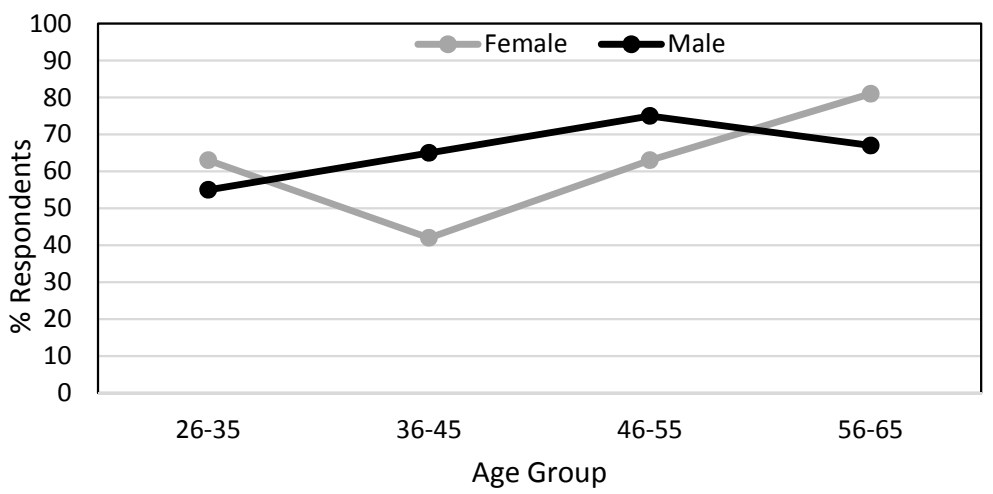

Figure 4. Fixed electricity price contracts chosen by the respondents grouped by age and gender.

Regarding variable pricing contracts (Figure 3), it was found that female respondent between 36 and 45 years old constituted the largest group, followed by males between $26-35$ and 56-65; however, 
there was no clear trend between age and preference towards variable pricing. On the contrary, on the fixed-price contracts, there was a more pronounced trend towards a higher preference for fixed-priced contracts with older age groups of both genders.

Although there was no particular question included in this survey that would help determine the actual reasons for this, the results confirm the finding described by the Swedish Energy Market Inspectorate, where age was found to have a significant, negative impact on preferences for variable-price contracts [22]. Additionally, as discussed in Hargreaves et al. [33], the elderly, who are in some way already involved in reducing their consumption, are the most resistant consumer group to participate in load-shifting strategies.

In a previous study carried out by Campillo et al. [24], it was indicated that the saving potential is larger with variable pricing, in houses and especially in those with electric heating, where the heat demand could be controlled by, e.g., smart thermostats that take into account the spot price for operating the heating system. For this reason, it is not surprising that eight out of the 13 people $(61 \%)$ who were willing to change to variable pricing live in detached houses. Additionally, 12 (32\% of the total households with electric heating) of the respondents with electric heating and that consider electricity savings to be "very important" or "important" have variable-price contracts. In general, the responses are consistent with the conclusions from previous findings, regarding consumers that feel more comfortable with lower financial risk, that is when they know what the price rate is going to be for at least one year ahead [53]. Based on the low interest in frequent energy consumption information ( $58 \%$ of the people that have fixed rates still prefer to receive electricity consumption information once a month), the results might suggest that a solution that could engage customers to switch to variable prices might be different levels of automation. Consumers preferring automation solutions, rather than deciding themselves and changing what would affect their energy usage, has been discussed in previous studies [53,54].

Additionally, of the respondents that consider saving electricity as something "important" or "very important", only $33 \%$ have variable-price contracts, while $62 \%$ have fixed tariffs. This link between the importance of reducing electricity consumption and the choice for variable-price contracts could be a result of the overall low average electricity prices in Sweden during the last few years, the lack of interest and the lack of tools that allow users to follow their consumption and price development, among others.

\subsection{Consumption Information and Feedback}

One of the aims with the questions used in this study was to understand the expectations and preferences of smart meter users regarding information about their electricity consumption.

Eighty percent of the respondents stated that at the moment of the survey, they did not use any device to follow their electricity consumption. Therefore, providing consumers with relevant and easy to understand information that would help them reduce their consumption still relies heavily on the electricity bill.

Although with the introduction of the smart electricity meters in Sweden, all electricity bills started being based on actual consumption and not estimated values, most electricity providers improved the bills (received monthly or once every two months) only by adding bar graphs showing monthly consumption. This practice, however, fails at fulfilling the qualities of "successful" feedback: access to relevant comparators (historical values, comparisons with similar households, targets or between users), a frequency more often than monthly, appliance-specific breakdown of usage or an interactive element [9,34].

The participants in this survey were asked to answer what type of additional information included in their electricity bills they think would help them reduce their consumption, the responses being presented in Figure 5. The respondents were given the possibility to select as many of the provided options as they wanted. 
The results presented in Figure 5 suggest that the majority of the respondents chose to have their electricity consumption disaggregated into the different appliances $(69 \%)$ and to receive specific electricity saving tips based on their own electricity consumption (62\%). Interestingly, very few respondents $(30 \%)$ chose to see their electricity consumption compared to their neighbors' electricity consumption, even though some studies have suggested that providing such information could help consumers reduce their consumption [55]. Results from a high number of participants, presented by OPOWER (Arlington County, VA, USA), a company that provides a large-scale, low-technology system for electricity billing in the United States, show reductions of $3 \%$ over the first two years of operation in 35,000 participants against a control group [9]. Issues related to privacy concerns could explain the unwillingness of comparing one's own electricity usage to other peers: the respondents might consider sharing their electricity usage with their neighbors as an invasion of their private life [56]. On this matter, results presented in Naus et al. [57] showed that, although Dutch consumers were eager to enhance existing energy management practices cooperating with suppliers and with fellow householders, their participation in new monitoring, production and time-shifting was highly dependent on their autonomy and privacy consideration.

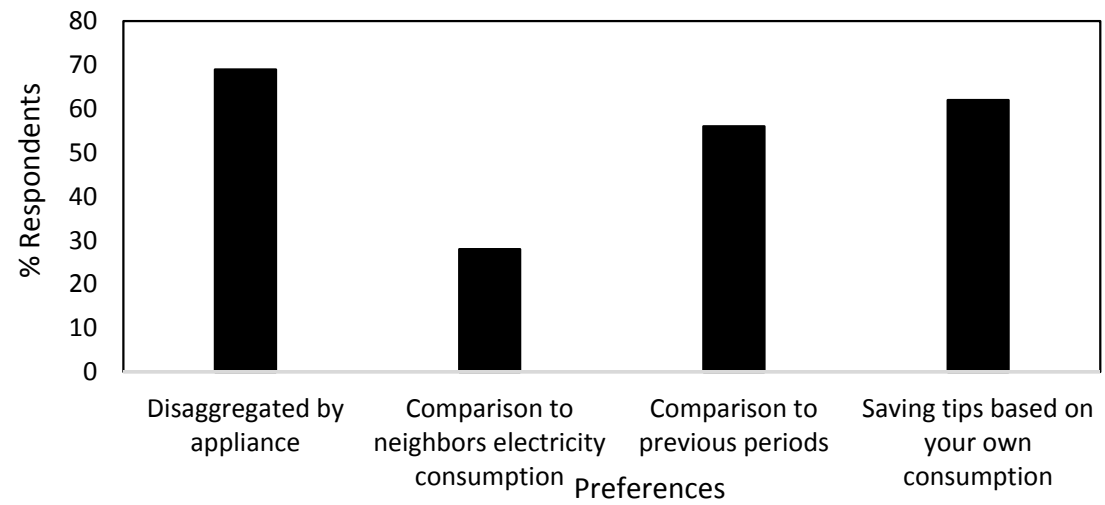

Figure 5. Type of information to be included in the electricity bills, chosen by the survey respondents $(N=164)$.

The preferred types of information were divided based on the respondents' age groups and are presented in Figure 6. In this case, respondents from the age groups of -25 and $66+$ were again excluded due to the low number of participants in these groups.

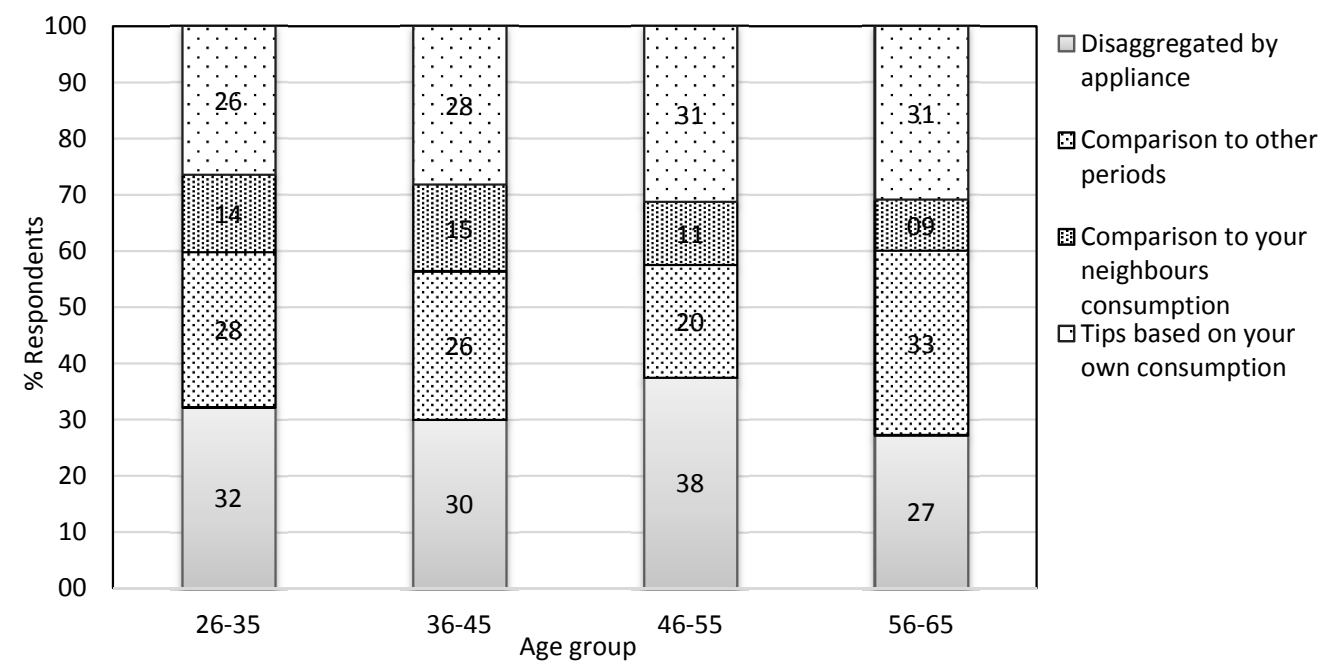

Figure 6. Type of information chosen by the respondents, by age group $(N=149)$. 
Since any of these types of information could be included in the electricity bill, the survey participants were given the possibility to select several of the provided responses. As the respondents were not asked to grade their choices (e.g., from most to least preferred), it is difficult to assess the differences between different age groups.

Within each one of the different age groups, "disaggregated by appliance" was the preferred type, except the group 56-65 years old, where "comparison to other periods" was the most preferred type with $33 \%$, followed by "tips on your own consumption" chosen by $31 \%$ of the respondents in this age group. For most age groups, the second most preferred information was "tips based on your own consumption". These findings are important, since they show that one of the first steps towards increasing consumer flexibility is for them to understand their appliances' electricity consumption and to be able to shift their use. The lack of knowledge regarding appliances' consumption has been presented in a study carried out by Chen et al. [58], where results showed that the average household in the studied sample overestimated the electricity used by lighting by $75 \%$, while underestimating plug-in devices by $29 \%$. By showing electricity consumption disaggregated by appliance, the consumers would additionally be able to notice inefficient appliances and find more efficient alternatives. Moreover, detailed appliance consumption information enables personalized recommendations [14], which is the second most preferred type of information selected by respondents in this study.

The frequency of providing feedback on electricity consumption is also considered an important factor, especially when targeting long-term effects on energy savings and behavioral changes, and for that reason, the participants in this study were asked about their preferences regarding the frequency at which they wanted to receive information about their consumption. The majority of the consumers chose "once per month" (57\%) as the desired frequency for receiving information about their consumption; followed by "every second month", 18\%, and "once a week", 15\%. These results suggest that the respondents are not very interested in real-time or daily consumption information (typically provided by IHD or apps, for instance) and could explain why the most preferred way of receiving information is "e-mail", as seen in Figure 7. Since the ways of showing information are not exclusive, participants were allowed to select several of the provided options.

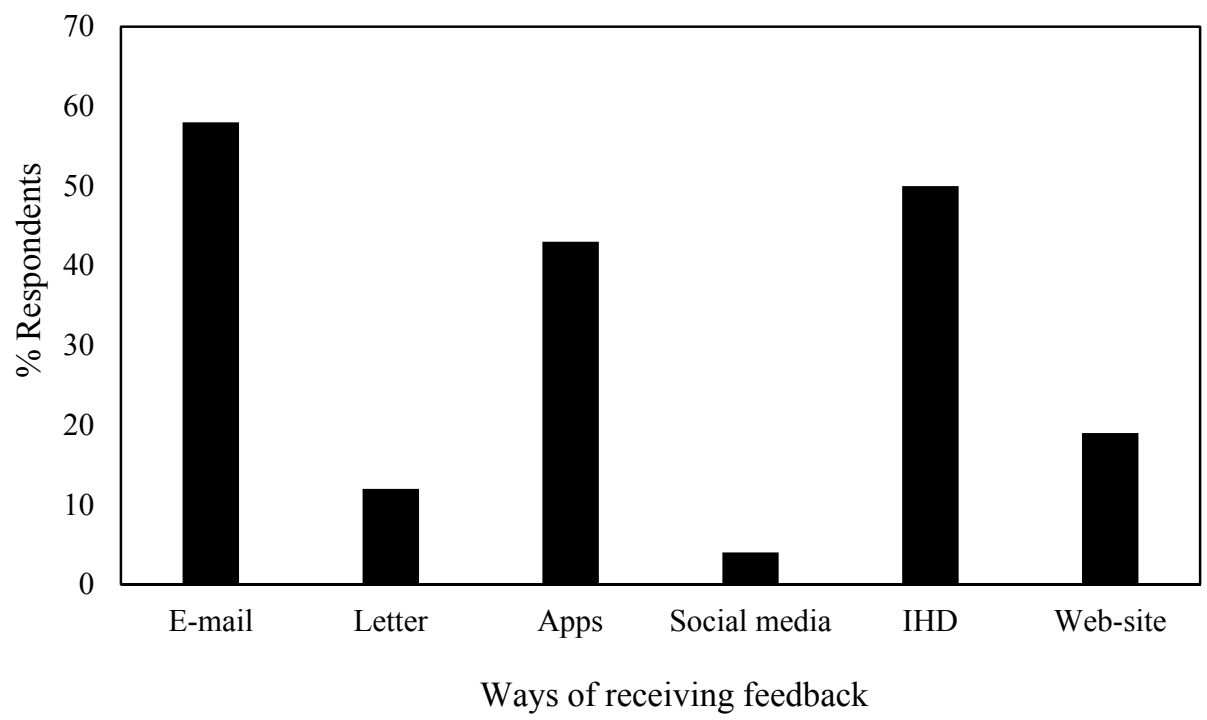

Figure 7. Most preferred methods of providing feedback chosen by the respondents $(N=164)$. IHD, in-home display.

The results regarding the most preferred methods for receiving information, when combined with the type of information that the respondents indicated that they want in their electricity bills, provide important insights that could be used by DSOs, policy or energy saving campaigns: even 
if information is not provided on a frequent basis, it is important to provide monthly information although specifying more in detail how to save energy or presenting the specific appliance-based consumption profiles. The detailed information that respondents asked for, despite being provided once a month, could lead to significant savings and efficiency by helping the consumers learn which appliances have the highest impact on their monthly consumption.

The overall high percentages of responses obtained for tools, such as in-home displays and "apps", in comparison to studies from previous years might be due to the improved performance and awareness created around these methods that made the respondents prefer them rather than, for instance, "web-site". A detailed analysis of what information and functionalities in-home displays need to include has been presented in Darby [9], where some of the users' preferences suggested: a clear analogue indicator of the current rate of consumption; the current rate of consumption as the rate of spending; cumulative daily spending; spending in the last seven days, day by day; spending in the last complete week; an option to switch units from money to power and energy; and the possibility to move the display in the home; among others. Hargreaves et al. [33] pointed out that the way the displays look also has a significant impact on the desire of consumers to use them; IHDs need to fit in the wider household, provide information that can be easily related to everyday practices and address whole households rather than individual ones.

Results presented in previous studies showed that the consumers' age has a strong impact on choosing the way of receiving consumption information [59]; therefore, responses regarding the way of receiving feedback were divided based on the respondents' age and are presented in Figure 8.

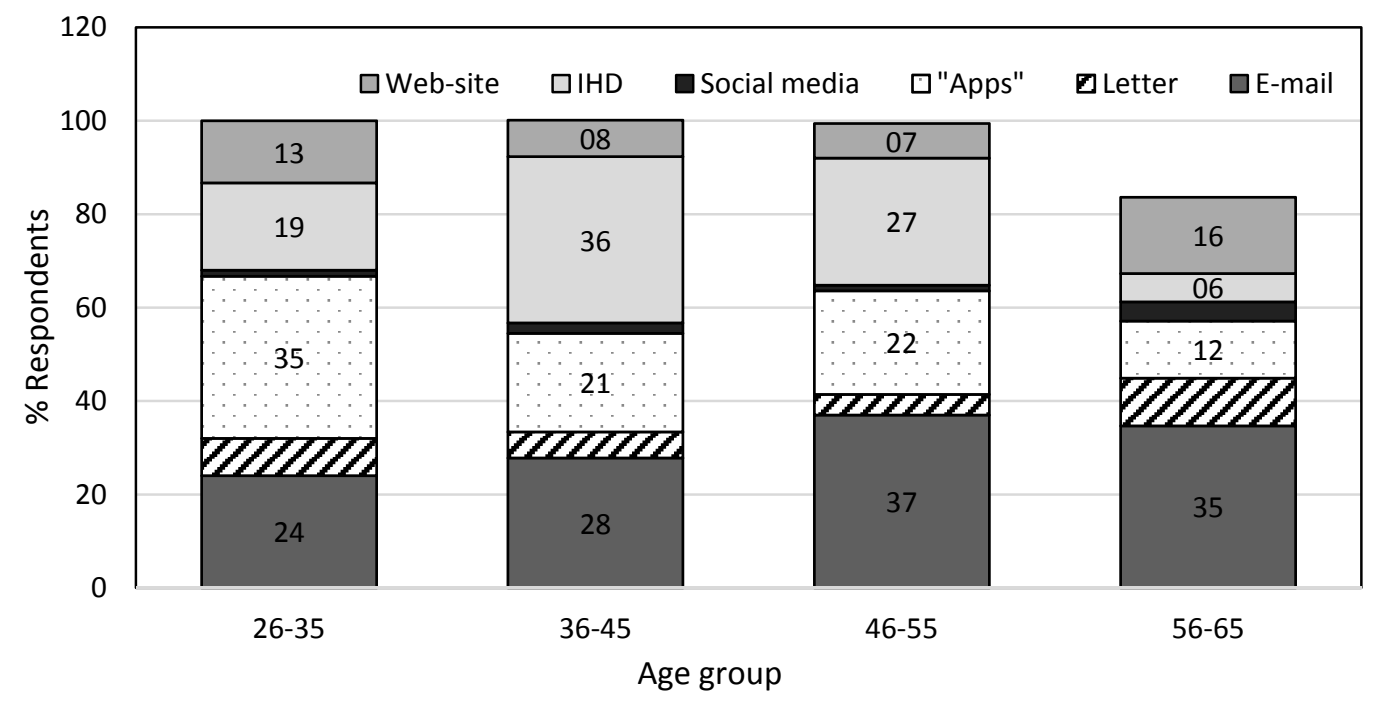

Figure 8. Selected electricity visualization tools, by age group $(N=149)$.

It is interesting to note that "apps" was selected as the most preferred method within the 26-35 years old group; while "e-mail" is the most or second most preferred method within all age groups. In-home displays were the most preferred for the respondents between $36-45$ years old; and the second most preferred for the 46-55 years old group. These results indicate the importance to not only adapt the type of information provided, but also the way it is delivered to different consumer groups, in order to create engagement and possible long-term effects.

The respondents were also divided into two groups based on the household main source of heating (electric or district heating, excluding the rest of the heating systems), since, as mentioned earlier, electricity savings could be more prominent in cases where electric heating is used, especially in climates with long and cold winter periods, as the case of Sweden. Moreover, the use of electricity for heating can be regulated by "intelligent" thermostats (which would turn off the heat when it is not needed or reduce the temperature without compromising comfort) and reduce peak energy 
consumption by $13 \%$ more than in cases where no enabling technologies were used [60]. In order for consumers with electric heating to adapt consumption based on price fluctuations, they need visualization methods that allow easy access to current prices.

Figure 9 shows higher preferences for "e-mail", "IHDs" followed by "apps" by the respondents, regardless of the type of heating system (district heating or electric heating) used by the customers, indicating that in the case that real-time pricing information can be provided to these consumers and help them regulate their heating accordingly, it is viable, and their most preferred tools (especially apps and in-home displays) can be used with this purpose.

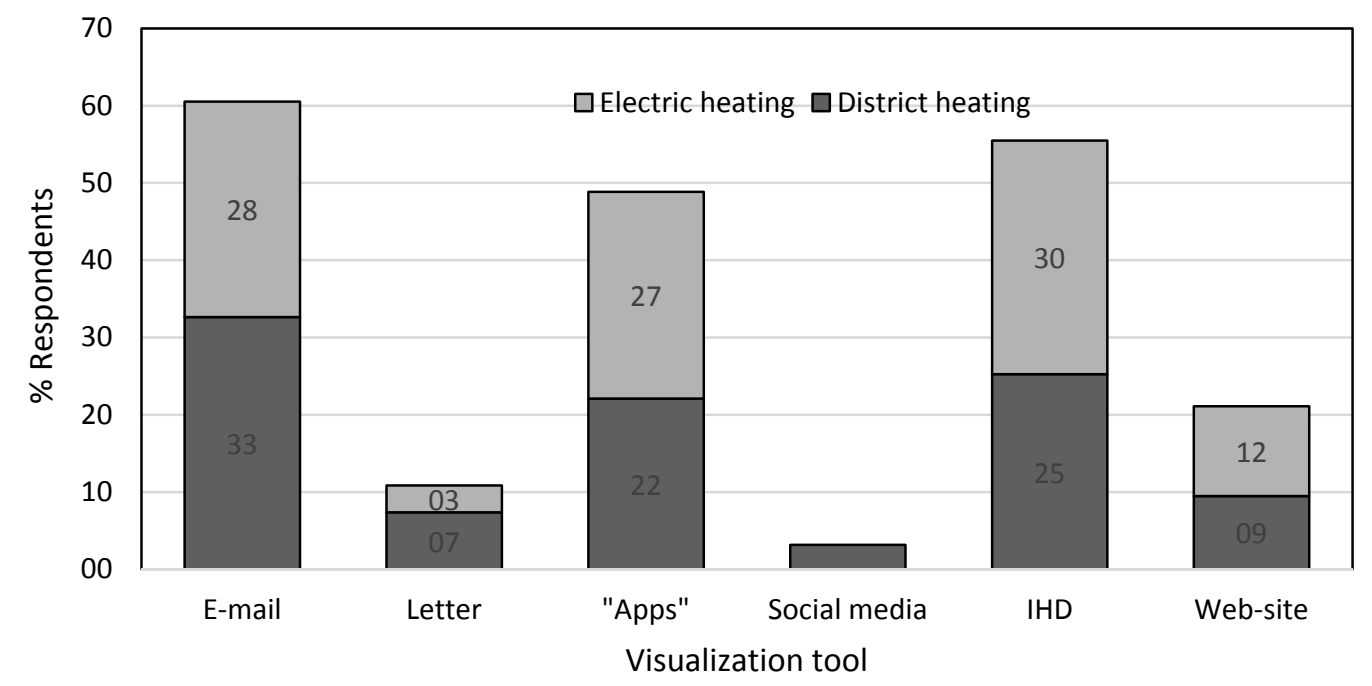

Figure 9. Most preferred ways of receiving feedback, based on the main heating system used by the respondents $(N=149)$.

Overall, the results presented in this study show that two of the methods currently used by most DSOs in Sweden (web-site and paper bills) to provide feedback on their customers' energy use were the least favorite among the respondents. The main challenge with the web-based information is that users need to make a conscious decision to specifically go to the web-site and use their credentials to access their energy information [9]. The results obtained suggest that customers are more interested in receiving information through communication channels they are more familiar with, that they can include into their daily routine and that require little or no additional effort. One of the current challenges is also to maintain the interest, knowledge and changed behaviors in the long term. Hargreaves et al. [61] indicated in a follow-up study (12 months after the initial interviews) that interviewees considered the placement of IHDs in communal areas, such as the kitchen, hallway or lounge, helped consumers engage for longer periods. However, the results showed that although the IHD users had quickly learned about their "normal" consumption, IHDs had become a mere "background" and embedded into everyday routines. Possible solutions to long-term engagement could be more radical regulations, combining energy consumption feedback with other kinds of information that is of the households' interest (e.g., weather conditions, bus schedules, etc.) or additional tips regarding new ways of saving energy even further and based on the households' consumption trends and interests.

\section{Conclusions}

Enhancing consumer empowerment by providing end-users with consumption information and access to variable prices that will help them better understand their energy consumption and consequently change their patterns and behavior has been one of the main expected outcomes from the large-scale adoption of smart meters. Sweden became one of the first countries to install smart 
meters for all electricity customers, making their perspective an important source of information when it comes to analyzing the progress in the use made of smart electricity meters.

In this paper, results from a web-based survey were used to understand and analyze customers' perception towards the current electricity consumption feedback information provided from smart electricity meters and their participation in the available variable-price contracts. The analysis of the survey included in this paper shows that consumers consider disaggregated energy usage of their appliances and personalized saving tips based on their own consumption to be key factors in helping them improve their energy efficiency. However, DSOs in Sweden are not yet offering these services as part of their standard services. Additionally, the methods of providing the information obtained from the smart meter infrastructure used currently by most DSOs, which are paper bills (letters) and web-sites, turned out to be the least preferred by the respondents included in this study.

On the contracts between customers and electricity providers, even though one of the main services smart meters provide customers with is the possibility to access variable pricing contracts, the adoption of RTP and TOU in Sweden is still rather low. What is more relevant in this study is that only a small amount (13\%) of those customers with fixed electricity prices is willing to switch to variable-price contracts. The lack of "real" hourly-based contracts, the lack of tools for following electricity price fluctuations and support regarding specific actions are the main factors that prevent higher consumer flexibility, higher efficiency and behavioral change.

Moreover, Sweden's overall low electricity prices cannot be used as the main and only factor to motivate consumers to shift or change their consumption patterns. Additional methods and clearer information about the implications of variable pricing adoption might be necessary to increase the adoption of this contract type and help customers to better understand how the electricity market works, especially during peak times. Some of these methods could comply with fit-and-forget strategies in order to attract conservative customers that are not interested in making frequent decisions about energy consumption, such as smart thermostats, sleep timers and energy management systems. Additionally, when choosing the type of electricity contracts, consumers should be offered information regarding the way the current electricity price will be provided to them in order to follow up and adjust their activities accordingly.

The main findings presented in this study suggest that, although smart meters offer the potential of providing customers with more detailed information about their energy consumption and give access to variable pricing contracts, this has not been fully exploited by the DSOs, and thus, the potential for energy savings through increased knowledge has not been fully reached.

With an expected coverage of $80 \%$ of smart meters for all consumers in Europe by the year 2022 , in order to fully take advantage of the potential from the adoption of these metering units for end-consumers, it is critical to acknowledge that electricity consumption information and dynamic pricing alone are not enough to reach the energy efficiency targets that have been adopted by many countries worldwide. It is therefore necessary to learn from the customer experiences from early adopters of the technology, as is the case for Sweden, where this study has been carried out. This study has shown that the type of information that is currently supplied from DSOs in Sweden, is not enough to engage consumers to increase their demand flexibility.

Moreover, environmental implications should also be addressed when providing customers with a commodity, the cost and environmental impact of which depend on the electricity mix used at the moment that it is being produced. For instance, in the Nordic market, when the electricity prices are low, this is usually a consequence of a low-carbon energy mix (e.g., hydro, nuclear and wind power), due to high carbon taxes. On the contrary, in other countries, such as the U.S., with the large contribution of coal-fired power plants in combination with low carbon taxes for electricity production in the mix, when electricity prices are low, the carbon contributions are higher. This could lead to a negative environmental impact if customers are only provided with electricity pricing information. Therefore, the information provided by the smart meters should be combined with additional data 
(e.g., real-time emissions per $\mathrm{kWh}$ ) in order to fully engage consumers and make the best use of smart meter data.

Based on the findings and issues discussed throughout the paper and given the current situation, policy and energy saving strategies should target consumers' needs to learn how the use of their appliances affects the consumption and the specific ways for achieving savings, in order to feel in control and become confident enough to shift activities, change behavior and, consequently, increase the efficiency.

The results presented in this study show that the potential of increasing residential energy efficiency through the active participation of informed customers from the information provided by the smart metering infrastructure is still very low, and more specific feedback should be provided from the acquired data. The development of incentives and "premium" packages with added value services (e.g., IHD) that would encourage consumers to make better use of their electricity, in the long term, could lead to smarter consumers that could adopt energy-efficient technologies and use them in the most efficient way.

Acknowledgments: The authors are grateful to the people working for Mälarenergi that contributed with their time and help with the survey distribution.

Author Contributions: Javier Campillo contributed with his knowledge and expertise in the analysis of electricity pricing data and information, as well as with the corresponding survey questions. Iana Vassileva contributed with writing the paper, the analysis of survey responses regarding feedback and information and with setting up the online survey and corresponding questions.

Conflicts of Interest: The authors declare no conflict of interest.

\section{References}

1. Energy in Sweden. 2013. Available online: https://energimyndigheten.a-w2m.se/Home.mvc?ResourceId=2785 (accessed on 4 May 2014).

2. Berkhout, P.H.G.; Muskens, J.C.; Velthuijsen, J.W. Defining the rebound effect. Energy Policy 2000, 28, 425-432. [CrossRef]

3. European Commission. A New Directive for Energy Efficiency-Challenges Addressed and Solutions Proposed. Available online: http://ec.europa.eu/energy/efficiency/eed/doc/2011_directive/20110622_energy_ efficiency_directive_slides_presentation_en.pdf (accessed on 5 May 2014).

4. European Commission. Energy Efficiency Directive. Available online: http://ec.europa.eu/energy/ efficiency/eed/eed_en.htm (accessed on 30 August 2014).

5. Smart Meters. Smart Electric Meters, Advanced Metering Infrastructure, and Meter Communications: Global Market Analysis and Forecasts; Navigant Consulting, Inc.: Boulder, CO, USA, 2013; p. 69.

6. Delivering Successful Smart Metering Projects in Europe. Available online: http://www.ey.com/ Publication/vwLUAssets/EY-delivering-successful-smart-metering-projects-in-Europe/\$FILE/

EY-delivering-successful-smart-metering-projects-in-Europe.pdf (accessed on 2 December 2015).

7. Gerpott, T.J.; Paukert, M. Determinants of willingness to pay for smart meters: An empirical analysis of household customers in Germany. Energy Policy 2013, 61, 483-495. [CrossRef]

8. Faruqui, A.; Sergici, S.; Sharif, A. The impact of informational feedback on energy consumption-A survey of the experimental evidence. Energy 2010, 35, 1598-1608. [CrossRef]

9. Darby, S. Smart metering: What potential for householder engagement? Build. Res. Inf. 2010, 38, 442-457. [CrossRef]

10. Pyrko, J.; Darby, S. Conditions of Behavioural Changes Towards Efficient Energy Use-A Comparative Study Between Sweden and the United Kingdom. Available online: http://www.lth.se/fileadmin/ees/ Publikationer/2009/8200_Pyrko.pdf (accessed on 31 August 2014).

11. Council of European Energy Regulators. Status Review of Regulatory Aspects of Smart Metering. Available online: http://www.energy-regulators.eu/portal/page/portal/EER_HOME/EER_PUBLICATIONS/ CEER_PAPERS/Customers/2013/7-1_C13-RMF-54-05-Status_Review_of_Regulatory_Aspects_of_Smart_ Metering_FOR_PUBLICATION.pdf (accessed on 20 March 2015). 
12. Swedish Energy Markets Inspectorate. Available online: http://erranet.org/Events/ERRA/2012/ Licensing_Gdansk_February (accessed on 1 December 2015).

13. Kerstin Sernhed. Energy Services in Sweden. Customers Relations Towards Increased Sustainability. 2008. Available online: http://www.ees.energy.lth.se/fileadmin/ees/Publikationer/2008/K_Sernhed_ DoctoralThesis2008.pdf (accessed on 1 December 2015).

14. Armel, C.K.; Gupta, A.; Shrimali, G.; Albert, A. Is disaggregation the holy grail of energy efficiency? The case of electricity. Energy Policy 2013, 52, 213-234. [CrossRef]

15. European Commission. The Commission's New Energy Efficiency Directive. Available online: http:/ / europa.eu/rapid/pressReleasesAction.do?reference=MEMO/11/440\&format=HTML\&aged=0 \&language $=$ en\&guiLanguage $=$ en (accessed on 5 May 2014).

16. Figueiredo, M.; de Almeida, A.; Ribeiro, B. Home electrical signal disaggregation for non-intrusive load monitoring (NILM) systems. Neurocomputing 2012, 9, 66-73. [CrossRef]

17. Benyoucef, D.; Klein, P.; Bier, T. Smart Meter with non-intrusive load monitoring for use in Smart Homes. In Proceeding of the 2010 IEEE International Energy Conference, Manama, Bahrain, 18-22 December 2010; pp. 96-101.

18. Zoha, A.; Ali, I.M.; Rajasegarar, S. Non-intrusive load monitoring approaches for disaggregated energy sensing: A survey. Sensors 2012, 12, 16838-16866. [CrossRef] [PubMed]

19. McKenna, E.; Richardson, I.; Thomson, M. Smart meter data: Balancing consumer privacy concerns with legitimate applications. Energy Policy 2012, 41, 807-814. [CrossRef]

20. Dütschke, E.; Paetz, A.-G. Dynamic electricity pricing-which programs do consumers prefer? Energy Policy 2013, 59, 226-234. [CrossRef]

21. Dupont, B.; de Jonghe, C.; Olmos, L.; Belmans, R. Demand response with locational dynamic pricing to support the integration of renewables. Energy Policy 2014, 67, 344-354. [CrossRef]

22. Swedish Energy Market Inspectorate. Available online: https://www.ei.se/Documents/Publikationer/ rapporter_och_pm/Rapporter\%202015/Rapport_An_electricity_market_in_transition_Umea_universitet.pdf (accessed on 29 November 2015).

23. Federal Energy Regulatory Commission (FERC). Assessment of Demand Response and Advanced Metering; Staff Report. Federal Energy Regulatory Commission (FERC): Washington, DC, USA, 2012. Available online: https:/ / www.ferc.gov/legal/staff-reports/12-20-12-demand-response.pdf (accessed on 18 December 2015).

24. Campillo, J.; Wallin, F.; Vassileva, I.; Dahlquist, E. Economic impact of dynamic electricity pricing mechanisms adoption for households in Sweden. In Proceeding of the World Renewable Energy Congress, Murdoch University Australia, Murdoch, Australia, 14-18 July 2103.

25. Hu, Z.; Kim, J.-H.; Wang, J.; Byrne, J. Review of dynamic pricing programs in the U.S. and Europe: Status quo and policy recommendations. Renew. Sustain. Energy Rev. 2015, 42, 743-751. [CrossRef]

26. Darby, S.J.; McKeena, E. Social implications of residential demand response in cool temperate climates. Energy Policy 2012, 49, 759-769. [CrossRef]

27. Peters, J.S.; Moezzi, M.; Lutzenhiser, S.; Woods, J.; Dethman, L.; Kunkle, R. Power Choice Residential Customer Response to TOU Rates, For California Energy Commission; Report CEC-5000-2009-XXX; Research into Action, Inc.: Berkeley, CA, USA, 2009.

28. Statistics Sweden (SCB). Negotiation and Changes of Electricity Contracts. 2014. Available online: http://www.scb.se/Statistik/EN/EN0304/2014K04/EN0304_2014K04_SM_EN24SM1501.pdf (accessed on 1 December 2015).

29. Heiskanen, E.; Matschoss, K. Exploring emerging customer needs for smart grid applications. In Proceeding of the 2nd IEEE PES International Conference and Exhibition on Innovative Smart Grid Technologies (ISGT Europe), Manchester, UK, 5-7 Decemebr 2011.

30. Broman Toft, M.; Schuitema, G.; Thøgersen, J. Responsible technology acceptance: model development and application to consumer acceptance of smart grid technology. Appl. Energy 2014, 134, 392-400. [CrossRef]

31. Throne-Holst, H.; Strandbakken, P.; Stø, E. Identification of households' barriers to energy saving solutions. Manag. Environ. Qual. Int. J. 2008, 19, 55-66. [CrossRef]

32. Energy in Sweden. Available online: https://www.energimyndigheten.se/contentassets/50a0c7046ce54aa88 e0151796950ba0a/energilaget-2015_webb.pdf (accessed on 30 Decemebr 2015).

33. Hargreaves, T.; Nye, M.; Burgess, J. Making energy visible: A qualitative field study of how householders interact with feedback from smart energy monitors. Energy Policy 2010, 39, 6111-6119. [CrossRef] 
34. Fischer, C. Feedback on household electricity consumption: A tool for saving energy? Energy Effic. 2008, 1, 79-104. [CrossRef]

35. Darby, S. The Effectiveness of Feedback on Energy Consumption: A review for DEFRA of the Literature on Metering, Billing and Direct Displays; Environmental Change Institute, University of Oxford: Oxford, UK, 2006.

36. Vassileva, I.; Odlare, M.; Wallin, F.; Dahlquist, E. The impact of consumers' feedback preferences on domestic electricity consumption. Appl. Energy 2012, 93, 575-582. [CrossRef]

37. Faruqui, A.; Harris, D.; Hledik, R. Unlocking the 53 billion savings from smart meters in the EU: How increasing the adoption of dynamic tariffs could make or break the EU's smart grid investment. Energy Policy 2010, 38, 6222-6231. [CrossRef]

38. Grønhøj, A.; Thøgersen, J. Feedback on household electricity consumption: Learning and social influence processes. Int. J. Consum. Stud. 2011, 35, 138-145. [CrossRef]

39. Göransson, A. Indicators for Electricity Consumption and End-Use, Elforsk Report 06:54. October 2006. Available online: http:/ / www.elforsk.se/Rapporter/?rid=06_54_(accessed on 29 November 2015).

40. Vaasaett. Assessing the Use and Value of Energy Monitors in Great Britain. Available online: http://www.vaasaett.com/wp-content/uploads/2014/04/assessing_the_use_and_value_of_energy_ monitors_in_great_britain-2.pdf (accessed on 10 December 2014).

41. Chiang, T.; Natarajan, S.; Walker, I. A laboratory test of the efficacy of energy display interface design. Energy Build. 2012, 55, 471-480. [CrossRef]

42. Bonino, D.; Corno, F.; de Russis, L. Home energy consumption feedback: A user survey. Energy Build. 2012, 47, 383-393. [CrossRef]

43. Vassileva, I.; Wallin, F.; Dahlquist, E. Understanding energy consumption behavior for future demand response strategy development. Energy 2012, 46, 94-100. [CrossRef]

44. Crouch, M.; McKenzie, H. The logic of small samples in interview-based qualitative research. Soc. Sci. Inf. 2006, 45, 483-499. [CrossRef]

45. Flyvberg, B. Five misunderstandings about case-study research. Qual. Inq. 2004, 12, 219-245. [CrossRef]

46. Braunsberger, K.; Whybenga, H.; Gates, R.A. Comparison of reliability between telephone and web-based surveys. J. Bus. Res. 2007, 60, 758-764. [CrossRef]

47. Fleming, C.H.M.; Bowden, M. Web-based surveys as an alternative to traditional mail methods. J. Environ. Manag. 2009, 90, 284-292. [CrossRef] [PubMed]

48. Vasteras City. Available online: http://www.vasteras.se/omvasteras/statistikochfakta/statistikafteramne/ Sidor/befolkning.aspx (accessed on 27 August 2014).

49. Survey System. Available online: http://www.surveysystem.com/sscalc.htm (accessed on 27 August 2014).

50. Ueno, T.; Inada, R.; Saeki, O.; Truji, K. Effectiveness of an energy-consumption information system for residential buildings. Appl. Energy 2006, 83, 868-883. [CrossRef]

51. Eurostat. Available online: http://ec.europa.eu/eurostat/statistics-explained/index.php/Household_ composition_statistics (accessed on 26 November 2015).

52. Statistics Sweden. Available online: http://www.scb.se/en_/Finding-statistics/Statistics-by-subject-area/ Housing-construction-and-building/Housing-construction-and-conversion/Dwelling-stock/Aktuell-Pong/ 87476/Behallare-for-Press/388316/ (accessed on 25 November 2015).

53. NordREG. Nordic Market Report 2011: Development in the Nordic Electricity Market; NordREG: København V, Danmark, 2011.

54. Karjalainen, S. Should it be automatic or manual-The occupant's perspective on the design of domestic control systems. Energy Build. 2013, 65, 119-126. [CrossRef]

55. Peschiera, G.; Taylor, J.E. The impact of peer network position on electricity consumption in building occupant networks utilizing energy feedback systems. Energy Build. 2012, 49, 584-590. [CrossRef]

56. Löfström, E. Smart meters and people using the grid: Exploring the potential benefits of AMR-technology. Energy Proced. 2014, 58, 65-72. [CrossRef]

57. Naus, J.; van Vliet, B.J.M.; Hendriksen, A. Householders as change agents in a Dutch smart energy transition: on power, privacy and participation. Energy Res. Soc. Sci. 2015, 9, 125-136. [CrossRef]

58. Chen, V.L.; Delmas, M.A.; Kaiser, W.J.; Locke, S.L. What can we learn from high frequency appliance-level energy metering? Results from a field experiment. Energy Policy 2015, 77, 164-175. [CrossRef] 
59. Vassileva, I.; Wallin, F.; Ding, Y.; Beigl, M.; Dahlquist, E. Household Indicators for Developing Innovative Feedback Technologies. In Proceedings of 2011 2nd IEE PES International Conference and Exhibition on Innovative Smart Grid Technologies (ISGT Europe), Manchester, UK, 5-7 December 2011.

60. Ivanov, C.; Getachew, L.; Fenrick, S.A.; Vittetoe, B. Enabling technologies and energy savings: The case of EnergyWise Smart Meter Pilot of Connexus Energy. Util. Policy 2013, 26, 76-84. [CrossRef]

61. Hargreaves, T.; Nye, M.; Burgess, J. Keeping energy visible? Exploring how householders interact with feedback from smart energy monitors in the longer term. Energy Policy 2013, 52, 126-134.

(C) 2016 by the authors; licensee MDPI, Basel, Switzerland. This article is an open access article distributed under the terms and conditions of the Creative Commons by Attribution (CC-BY) license (http://creativecommons.org/licenses/by/4.0/). 